\title{
Estimating field-scale root zone soil moisture using the cosmic-ray neutron probe
}

\author{
Amber M. Peterson ${ }^{1,2}$, Warren D. Helgason ${ }^{1,2}$, and Andrew M. Ireson ${ }^{2,3}$ \\ ${ }^{1}$ Department of Civil and Geological Engineering, University of Saskatchewan, Saskatoon, Saskatchewan, Canada \\ ${ }^{2}$ Global Institute for Water Security, University of Saskatchewan, Saskatoon, Saskatchewan, Canada \\ ${ }^{3}$ School of Environment and Sustainability, University of Saskatchewan, Saskatoon, Saskatchewan, Canada \\ Correspondence to: Warren D. Helgason (warren.helgason@usask.ca)
}

Received: 17 November 2015 - Published in Hydrol. Earth Syst. Sci. Discuss.: 10 December 2015

Accepted: 6 March 2016 - Published: 7 April 2016

\begin{abstract}
Many practical hydrological, meteorological, and agricultural management problems require estimates of soil moisture with an areal footprint equivalent to field scale, integrated over the entire root zone. The cosmic-ray neutron probe is a promising instrument to provide field-scale areal coverage, but these observations are shallow and require depth-scaling in order to be considered representative of the entire root zone. A study to identify appropriate depthscaling techniques was conducted at a grazing pasture site in central Saskatchewan, Canada over a 2-year period. Areaaveraged soil moisture was assessed using a cosmic-ray neutron probe. Root zone soil moisture was measured at 21 locations within the $500 \mathrm{~m} \times 500 \mathrm{~m}$ study area, using a downhole neutron probe. The cosmic-ray neutron probe was found to provide accurate estimates of field-scale surface soil moisture, but measurements represented less than $40 \%$ of the seasonal change in root zone storage due to its shallow measurement depth. The root zone estimation methods evaluated were: (a) the coupling of the cosmic-ray neutron probe with a time-stable neutron probe monitoring location, (b) coupling the cosmic-ray neutron probe with a representative landscape unit monitoring approach, and (c) convolution of the cosmicray neutron probe measurements with the exponential filter. The time stability method provided the best estimate of root zone soil moisture $\left(\mathrm{RMSE}=0.005 \mathrm{~cm}^{3} \mathrm{~cm}^{-3}\right.$ ), followed by the exponential filter (RMSE $=0.014 \mathrm{~cm}^{3} \mathrm{~cm}^{-3}$ ). The landscape unit approach, which required no calibration, had a negative bias but estimated the cumulative change in storage reasonably. The feasibility of applying these methods to field sites without existing instrumentation is discussed. Based upon its observed performance and its minimal data require-
\end{abstract}

ments, it is concluded that the exponential filter method has the most potential for estimating root zone soil moisture from cosmic-ray neutron probe data.

\section{Introduction}

Root zone soil moisture stored in roughly the top metre of the unsaturated zone is an important regulator of both the hydrological and energy cycle. It places an important control on evapotranspiration in water-limited environments, and influences the partitioning of latent and sensible heat, having a marked effect on the near-surface state of the atmosphere. Soil moisture is a state variable in the water balance equations of many hydrological, meteorological, and agricultural models; thus, accurate observations of root zone soil moisture over large spatial extents are indispensable for model validation (Grayson and Western, 1998), and for run-time assimilation (e.g. Brocca et al., 2010a). The required spatial scale greatly depends on the application. At very large scales, active and passive remote sensing instruments attached to satellites (e.g. the Soil Moisture and Ocean Salinity (SMOS) mission) have the potential to measure and map soil moisture globally (Kerr et al., 2010), but have coarse resolutions $(35-50 \mathrm{~km})$. Soil moisture observations at finer scales, such as field scale $\left(0.1-1 \mathrm{~km}^{2}\right)$, are often required for understanding hydrological processes (e.g. water balance studies) or for use in agricultural applications (irrigation scheduling, crop water use monitoring, etc.). The cosmic-ray neutron probe uniquely fills the measurement scale gap between remote sensing techniques and point-scale observing methods, pro- 
viding observations of average soil moisture over a $\sim 240 \mathrm{~m}$ radius footprint (maximum radius as determined by Köhli et al., 2015). Cosmic-ray neutron probes have been shown to be successful in measuring field-scale soil moisture in a variety of environments and regions (e.g. Rivera Villarreyes et al., 2011; Franz et al., 2012a; Bogena et al., 2013; Hawdon et al., 2014), and have potential for validating remote sensing data (Crow et al., 2012; Hornbuckle et al., 2012; Dong et al., 2014). The cosmic-ray neutron probe holds great promise; however, the effective measurement depth is less than $30 \mathrm{~cm}$ for most soils (Franz et al., 2012b), requiring upscaling with depth to be representative of the entire root zone.

In this study, we extend the depth of the field-scale cosmicray neutron probe measurements by coupling them with an estimate of the deeper root zone soil moisture that has been determined by two main approaches: upscaling point measurements, and modelling.

The three methods considered to upscale the deeper measurement to the same areal extent as the cosmic-ray neutron probe were: (1) averaging of multiple point-scale measurements, (2) using a single time-stable measurement location to represent the large-scale spatial average, and (3) disaggregating the larger area into a few landscape units which can be represented by single monitoring locations. Multi-point averaging is the simplest way to upscale a network of point measurements. With a large number of measurement points this method can be accurate; however, to implement such a monitoring scheme in practice is often not feasible. The other methods considered allow areal soil moisture to be monitored from a greatly reduced number of points. In the time stability approach, a single site having a soil moisture response similar to that of the areal average is used to estimate the field-scale moisture content. Since the method was first proposed by Vachaud et al. (1985), time-stable sites have been found in a variety of environments (e.g. Grayson and Western, 1998; Mohanty and Skaggs, 2001; Teuling et al., 2006; Brocca et al., 2010b; Zhao et al., 2010; Gao et al., 2013). However, this approach often requires an extensive investigation in order to identify a time-stable soil moisture location (Teuling et al., 2006). In the landscape monitoring approach, the number of point measurements needed to estimate fieldscale soil moisture is reduced to the number of representative landscape units. Landscape features that influence the spatial variability of soil moisture, such as vegetation and topography, are relatively easy to visually assess (Hawley et al., 1983) and form a convenient conceptual model from which to build a simplified soil moisture monitoring strategy. The main challenge associated with this approach is identifying the appropriate controlling factors for which to disaggregate the landscape.

The assimilation of remotely sensed near-surface soil moisture data into water balance models to obtain profile soil moisture has been attempted and shown to provide good results (e.g. Ragab, 1995; Calvet and Noilhan, 2000; Walker et al., 2001; Heathman et al., 2003). Soil moisture collected from cosmic-ray neutron probe installations have also been assimilated into models with similar complexity, such as the NOAH land surface model (Shuttleworth et al., 2013; Rosolem et al., 2014), Community Land Model (Han et al., 2015), and HYDRUS-1D (Rivera Villareyes et al., 2014). In the present study we combine the cosmic-ray neutron probe data with a simpler modelling approach, termed the exponential filter method or soil water index (SWI) method. This method, introduced by Wagner et al. (1999), is based on a two-layer soil water balance. The soil moisture of the deeper layer (layer 2) is estimated as a function of the previous layer 2 estimate and the current surface (layer 1) soil moisture measurement; the importance of these two terms are determined by an exponential filter. The exponential filter model has been successfully applied to remotely sensed data from the ERS Scatterometer (Wagner et al., 1999; Ceballos et al., 2005), Advanced Scatterometer (Albergel et al., 2009), and SMOS (Ford et al., 2014).

The following sections describe the experimental approach used to apply and validate the depth-scaling techniques considered. Performance of the techniques in terms of estimating field-scale volumetric water content and moisture changes were evaluated using 2 years of data collected from a prairie pasture in central Saskatchewan, Canada. The feasibility of applying the methods at locations without existing instrumentation is also discussed. A conclusion is reached on which of the methods is most suitable for estimating root zone soil moisture from cosmic-ray neutron probe data.

\section{Methods}

\subsection{Study site}

The study site is within a grazing pasture, located an hour south of Saskatoon, SK in the Brightwater Creek watershed $\left(51^{\circ} 22^{\prime} 54^{\prime \prime} \mathrm{N}, 106^{\circ} 24^{\prime} 57^{\prime \prime} \mathrm{W}\right)$. The perennial vegetation primarily consists of various wheatgrasses (Agropyron sp.) and needlegrasses (Stipa sp.) with patches of western snowberry (Symphoricarpos occidentalis) (Fig. 1a). The areal fractions of grass and shrub were surveyed to be 54 and $46 \%$, respectively. Topography is of low relief, varying $\sim 5 \mathrm{~m}$ over the $500^{2} \mathrm{~m}^{2}$ study area (Fig. 1b). The dominant soil type is dark brown Solonetz of the Rosemae association (Ellis et al., 1970). The climate is semi-arid, and the winters are characterized as cold. The regional average yearly precipitation is $298 \mathrm{~mm}$ rain and $78 \mathrm{~mm}$ snow water equivalent; and average daily temperatures are $-15.3^{\circ} \mathrm{C}$ in January and $18.0^{\circ} \mathrm{C}$ in July (climate normals from Davidson (Environment Canada, 2014), a community $32 \mathrm{~km}$ from the site). The period of interest for this study is the warm months (May-October) when the soil is unfrozen and significant changes in soil moisture occur. 

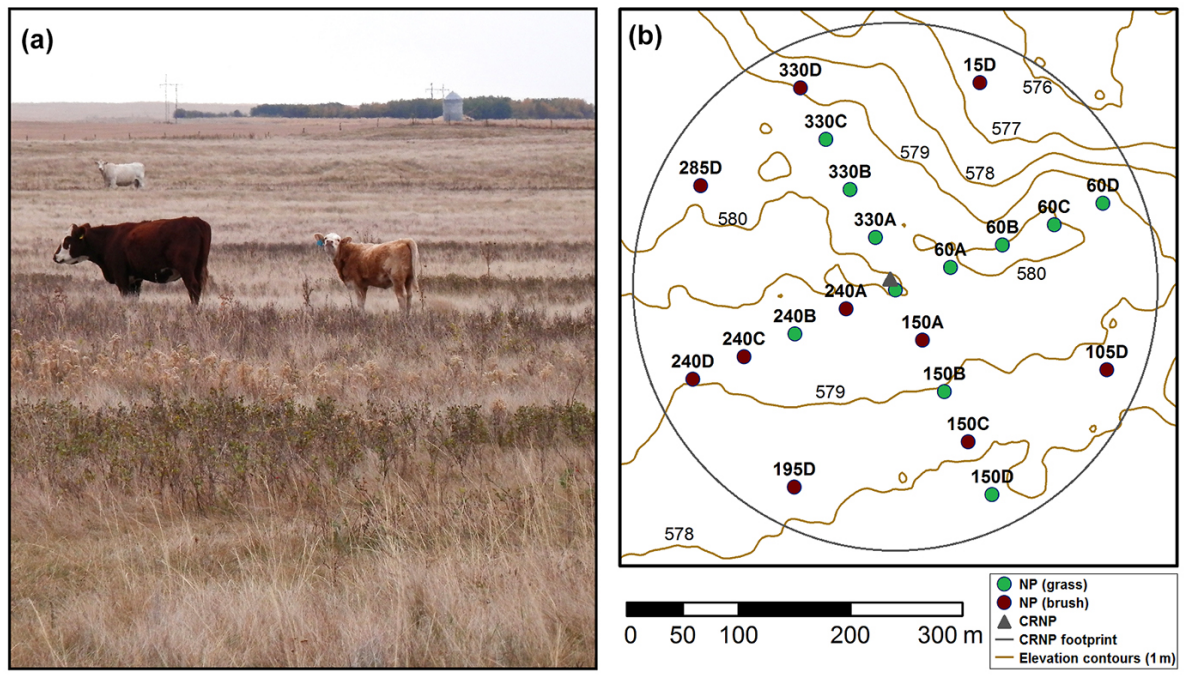

Figure 1. Experimental site: (a) photo of the pasture, and (b) map showing elevation contours and the locations of soil moisture instrumentation.

\subsection{Ground-based observations}

\subsubsection{Cosmic-ray neutron probe}

Continuous measurements of field average surface soil moisture were obtained using a cosmic-ray neutron probe (Model CRS-1000, Hydroinnova LLC, USA). Cosmic-ray neutron probes monitor the levels of cosmic-ray fast neutrons (naturally produced background radiation) found near the earth's surface. Fast neutrons are most effectively slowed by hydrogen, and therefore the quantity of fast neutrons detected by the probe can be related to soil moisture. The neutron counts detected by the probe were converted to volumetric soil moisture $\left(\theta_{\mathrm{v}}\right)$ using the equation from Hawdon et al. (2014),

$\theta_{\mathrm{v}}=\left(\frac{0.0808}{\left(\frac{N_{\text {corr }}}{N_{\mathrm{o}}}\right)-0.372}-0.115-w_{\text {lat }}-w_{\mathrm{SOM}}\right) \rho_{\mathrm{bd}}$,

where $N_{\mathrm{o}}$ is the neutron intensity over dry soil, and $N_{\text {corr }}$ is the corrected neutron counts. The neutron counts were corrected for air pressure, atmospheric water vapour, and incoming neutron intensity using the method outlined in Zreda et al. (2012). Soil samples were taken on 3 July 2013 to calibrate $N_{\mathrm{o}}$ and determine site-specific parameters. At the pasture site, the $0-15 \mathrm{~cm}$ dry soil bulk density $\left(\rho_{\mathrm{bd}}\right)$ is $1.13 \mathrm{~g} \mathrm{~cm}^{-3}$; lattice water ( $w_{\text {lat }}$ ) is $0.03 \mathrm{~g} \mathrm{~g}^{-1}$. Soil organic matter ( $w_{\mathrm{SOM}}$ ) was estimated to be $0.05 \mathrm{~g} \mathrm{~g}^{-1}$. The effective measurement depth $\left(z^{*}\right)$, an important factor for depth scaling, varies with changes in volumetric water content. The relationship determined by Franz et al. (2012b), with the inclusion of soil organic matter, is

$$
z^{*}=\frac{5.8}{\rho_{\mathrm{bd}} \cdot\left(w_{\text {lat }}+w_{\text {SOM }}\right)+\theta_{\mathrm{v}}+0.0829} .
$$

Neutron counts were integrated over the period of $1 \mathrm{~h}$, and the $12 \mathrm{~h}$ running averages of soil moisture were created as a way to smooth the noisy data signal (Zreda et al., 2012). Daily values of soil moisture from the cosmic-ray neutron probe are used in this study, and defined as the $12 \mathrm{~h}$ running average centred about noon. To validate the cosmic-ray neutron probe, gravimetric soil samples for a depth of $0-20 \mathrm{~cm}$ were obtained at 20 randomly selected points within the footprint on 9 August, 11 September, 30 September, and 23 October 2013. A distance-weighted average was calculated using the method in Köhli et al. (2015).

\subsubsection{Neutron probe array}

Point measurements of root zone soil moisture were taken using a down-hole neutron moisture metre (CPN 503DR Hydroprobe, CPN International Inc., USA) at $50 \mathrm{~m}$ spacing in a wheel-and-spoke pattern (Fig. 1b), to coincide with the radial footprint of the cosmic-ray neutron probe. For each of the 21 locations, soil moisture was measured at $20 \mathrm{~cm}$ increments from $20-160 \mathrm{~cm}$. A site-specific calibration $\left(\mathrm{RMSE}=0.025 \mathrm{~cm}^{3} \mathrm{~cm}^{-3}\right.$ ) was developed from soil cores taken in $20 \mathrm{~cm}$ increments during the installation of the aluminum access tubes. Soil moisture, at all locations within the array, were measured bi-weekly in 2013 and monthly in 2014.

\subsubsection{Meteorological data}

Precipitation was measured using an all-weather precipitation gauge (T-200B, Geonor, Inc., USA). Ancillary meteorological instrumentation, including air temperature and pres- 
sure, are located beside the centre neutron probe location, along with the cosmic-ray neutron probe.

\subsection{Field-scale soil moisture estimation techniques}

The methods used to estimate field-scale root zone soil moisture are described in this section. In all the methods, soil moisture is integrated over a $110 \mathrm{~cm}$ depth. The first three methods involve coupling the shallow soil moisture measured by the cosmic-ray neutron probe with the deeper area-scaled estimates from the neutron probe array. The fourth method only requires measurements from the cosmic-ray neutron probe after calibration. The performance of the methods for estimating field-scale volumetric water content and changes in storage will be assessed using four metrics: Pearson correlation coefficient $(R)$, root mean square error (RMSE), bias (BIAS), and Nash-Sutcliffe efficiency (NSE).

\subsubsection{Spatial average}

This approach couples the cosmic-ray neutron probe with the average of all available (21) point-scale measurements from the neutron probe array. Measurements are integrated over depth, and the field-scale soil moisture, $\theta_{(\mathrm{F})}$, is given by:

$\theta_{(\mathrm{F})}=\frac{\sum_{j=1}^{n} \sum_{i=1}^{m} \frac{\theta_{i, j}}{m} \cdot \Delta z_{j}}{z_{n}}$,

where $\theta_{i, j}$ is the volumetric water content for location $i$ and measurement depth $j, m$ is the number of measurement locations, $n$ is the number of measurement depths, $\Delta z_{j}$ is the thickness of the soil represented by the measurement depth, and $z_{n}$ is the total measurement depth. In this method, we use a changing measurement depth for the cosmic-ray neutron probe whereby the thickness of soil represented by the $20 \mathrm{~cm}$ measurement in the neutron probe array is $30 \mathrm{~cm}$ minus the effective depth of the cosmic-ray neutron probe. For all other methods, we assume the effective depth of the cosmic-ray neutron probe is constant.

The accuracy of the spatial average method is dependent on the estimates of field-scale soil moisture from both the cosmic-ray neutron probe and neutron probe array being accurate. Applying the statistical method found in Jacobs et al. (2004), which assumes soil moisture follows a normal distribution at $95 \%$ confidence, the error when using 21 point measurements will be less than $\pm 0.014 \mathrm{~cm}^{3} \mathrm{~cm}^{-3}$. By using a large number of point measurements it is assumed that the error between actual field-scale soil moisture and the value estimated by averaging has been minimized. This method is assumed to provide the best field-scale estimate and will be used to measure the performance of the other methods.

\subsubsection{Time stability}

This approach couples the cosmic-ray neutron probe with a single time-stable location in the neutron probe array. The concept of time stability is the idea that throughout time there will be sites that maintain their ranking in a distribution function, i.e. sites that continually exhibit field averages or extremes. The mean relative difference (MRD) method, demonstrated by Vachaud et al. (1985) to be successful in determining time-stable sites, is defined as:

$\operatorname{MRD}_{i, j}=\frac{\theta_{i, j}-\overline{\theta_{j}}}{\overline{\theta_{j}}}$,

where $\theta_{i, j}$ is the soil moisture measured at location $i$ and time $j$, and $\bar{\theta}_{j}$ is the average of all soil moisture measurements at time $j$. The measurement point with the smallest standard deviation in MRD over the monitoring period is considered the most time stable. However, the most timestable point is not necessarily representative of field average unless the average MRD for that point is zero. An offset $(\delta)$ is therefore needed to convert soil moisture measured at the time-stable site $\left(\theta_{\mathrm{TS}}\right)$ to field average $\left(\theta_{(\mathrm{F})}\right)$ :

$\theta_{(\mathrm{F})}=\theta_{\mathrm{TS}}+\delta$,

in which $\delta$ is the temporal average of the difference between the soil moisture at the time-stable site and that of the field (MRD numerator).

\subsubsection{Landscape unit}

This approach couples the cosmic-ray neutron probe measurements with deeper soil moisture measurements upscaled using a representative landscape unit, which in this case is based on vegetation type. It assumes that all soil moisture under a particular vegetation type is similar. A single monitoring site representing each vegetation type is used and fieldscale moisture storage, $\theta_{(\mathrm{F})}$, was calculated as:

$\theta_{(\mathrm{F})}=\sum_{i=1}^{n}\left(A_{i} \cdot \theta_{i}\right)$,

where $A_{i}$ and $\theta_{i}$ are the area fraction and depth-weighted soil moisture of vegetation type $i$, respectively. To apply the landscape unit monitoring approach at the study site, a single grass and brush monitoring location was chosen by subjectively picking the location that visually appears to be most representative of each vegetation type. Location $60 \mathrm{~A}$ was chosen as the grass monitoring site, and location $150 \mathrm{C}$ was chosen as the brush monitoring site. Both sites are typical of the distinct high-density grass and brush patches that can be seen in Fig. 1a. A two-tailed independent samples $t$ test was used to determine whether the mean soil moisture and moisture changes between the two groups were statistically different. 


\subsubsection{Exponential filter}

This approach uses the field-scale surface soil moisture measurements of the cosmic-ray neutron probe to model root zone soil moisture. This model, developed by Wagner et al. (1999), considers the water balance of a two-layer soil profile, where layer 1 is the surface layer in which field-scale soil moisture is measured, and layer 2 is the lower soil layer of interest for modelling. Soil moisture of layer $2\left(\theta_{2}\right)$ is described by a simple water balance as:

$L \frac{\mathrm{d} \theta_{2}}{\mathrm{~d} t}=C\left(\theta_{1}-\theta_{2}\right)$,

where $t$ is time, $L$ is the depth of layer 2, and $C$ is a proportionality constant. This approach assumes that transpiration and drainage losses from the lower layer are negligible, and that hydraulic diffusivity (i.e. the ratio of hydraulic conductivity to specific storage) between the soil layers is constant (Wagner et al., 1999). The recursive formulation of the solution for Eq. (7) using an exponential filter (Albergel et al., 2008) can be rearranged as:

$\mathrm{SWI}_{2(t)}=\mathrm{SWI}_{2(t-1)} \cdot\left(1-K_{t}\right)+\mathrm{SWI}_{1(t)} \cdot K_{t}$,

where $\mathrm{SWI}_{2}$ and $\mathrm{SWI}_{1}$ are the soil water index of layer 2 and layer 1, respectively, $t$ is a time index, and $K_{t}$ is the gain. Soil water index is the volumetric water content scaled $0-1$ using assumed minimum and maximum values. For layer 1, the volumetric water content is bounded by the minimum and maximum of the observations. For layer 2, water content can be bounded using wilting point as the minimum value, and the mid-point between field capacity and total water storage as the maximum value (Wagner et al., 1999). Soil data are therefore a necessary model input. The gain $\left(K_{t}\right)$, which ranges $0-1$, is calculated as:

$K_{t}=\frac{K_{t-1}}{K_{t-1}+\exp (-(\Delta t) / T)}$,

where $K_{t-1}$ is the gain of the previous time, $\Delta t$ is the time step, and $T$ is a characteristic time length (equal to $L / C$ from Eq. 7). The filter is initialized by setting $K_{1}=1$ and $\mathrm{SWI}_{2(1)}=\mathrm{SWI}_{1(1)}$. The characteristic time length $(T)$ is dependent on a variety of factors, including thickness of layer 2, and soil properties (i.e. hydraulic conductivity, texture, density) that may influence water transmission rates (Albergel et al., 2008); and therefore requires calibration. For this study, layer 2 minimum and maximum also needed calibration, as the soil data from a large-scale survey (Ellis et al., 1970) proved to be unsatisfactory (described in Sect. 3.3.3). A Monte Carlo simulation was used to calibrate the three parameters simultaneously. A range for each parameter was first assumed, and 100000 random combinations were generated. The optimum parameters were the set that had the highest NSE. A perfect model would have a NSE of 1, whereas a NSE of 0 or less indicates that modelled layer 2 SWI is no better than using the season average of the neutron probe array.

\subsection{Data selection}

Soil moisture data are available for the months of MayNovember in 2013 and 2014. Calibration was required for upscaling by time stability and the use of the exponential filter. For these methods, 2013 is used as the calibration period and 2014 as the validation period. Meteorological data from the site showed that 2014 was wetter and cooler than 2013. May-August precipitation was $141 \mathrm{~mm}$ in 2013 and $206 \mathrm{~mm}$ in 2014 , and average air temperature was 15.8 and $15.0^{\circ} \mathrm{C}$, respectively.

\section{Results and discussion}

\subsection{Near-surface soil moisture measured by the cosmic-ray neutron probe}

The soil moisture measured by the cosmic-ray neutron probe is shown in Fig. 2 for the 2013 and 2014 growing seasons, along with the measured daily precipitation and modelled effective measurement depth. The soil moisture, calculated using Eq. (1), was based on the single calibration date (3 July 2013). To provide validation of these measurements, gravimetric samples were taken on four occasions during summer of 2013, and are presented in Fig. 2 as the mean value $\pm 1 \mathrm{SD}(n=20)$. The mean surface soil moisture from the gravimetric samples is well matched by the cosmicray neutron probe. Differences in soil moisture between the cosmic-ray neutron probe and the point measurement averages may be in part due to differences in measurement depth. The gravimetric samples were from the top $20 \mathrm{~cm}$. The effective depth of the cosmic-ray neutron probe ranged between 7 and $21 \mathrm{~cm}$, with a mean depth of $14 \mathrm{~cm}$.

\subsection{Soil moisture variability with depth}

The spatial variability of soil moisture with depth is examined in Fig. 3a and b using the 2013 observations from the neutron probe array. The boxplots show consistent spatial variability of volumetric water content with depth, with the average moisture content difference between the 25 th and 75 th percentile being $0.07 \mathrm{~cm}^{3} \mathrm{~cm}^{-3}$. When looking at the seasonal change in soil moisture with depth (Fig. 3c), it can be seen that the temporal variability is high for shallower soil moisture, and low for deeper soil moisture. Although the spatial variability is similar for all depths, there is very little change in soil moisture below $100 \mathrm{~cm}$. The 2014 data showed similar variability characteristics with depth.

Next, we combined the shallow soil moisture observations from the cosmic-ray neutron probe with the deeper 21-point averaged neutron probe observations to construct a time series of field-scale water content with depth. The cumulative change in soil moisture storage over different depth intervals is shown in Fig. 4. The majority of the temporal change in moisture storage over the 2013 and 2014 growing seasons 

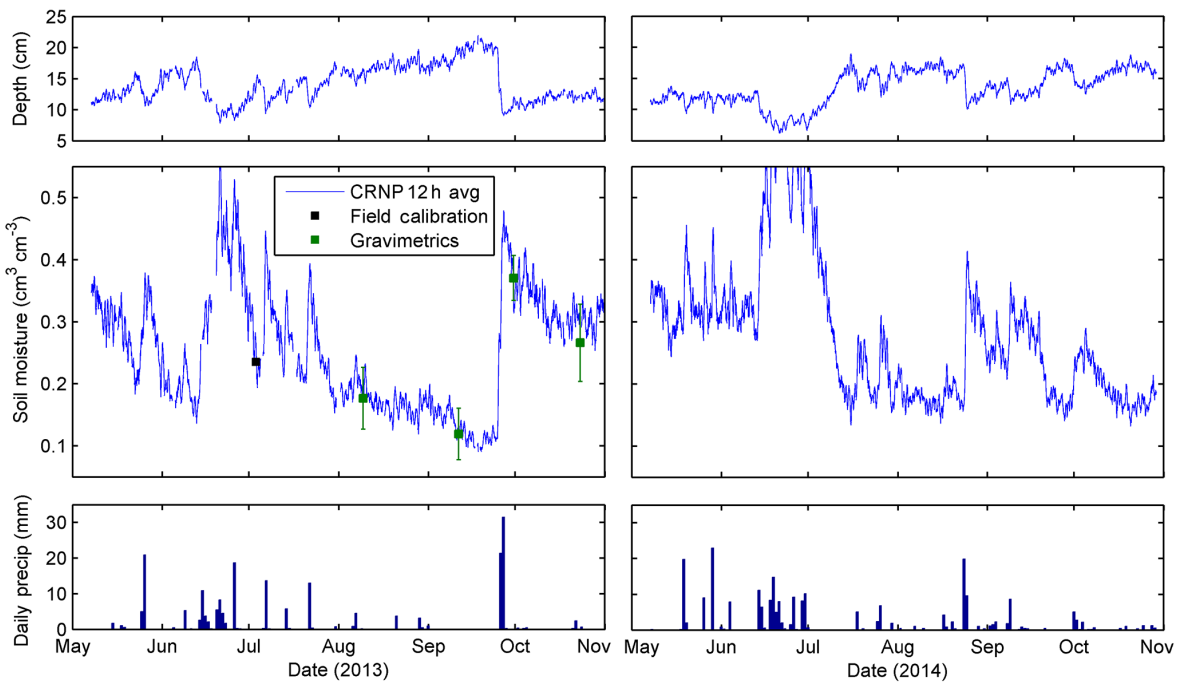

Figure 2. Field average soil moisture measured by cosmic-ray neutron probe ( $12 \mathrm{~h}$ running average), as compared to gravimetric soil samples (average \pm 1 SD) and precipitation for 2013 and 2014. The changing measurement depth is shown in the top graph.
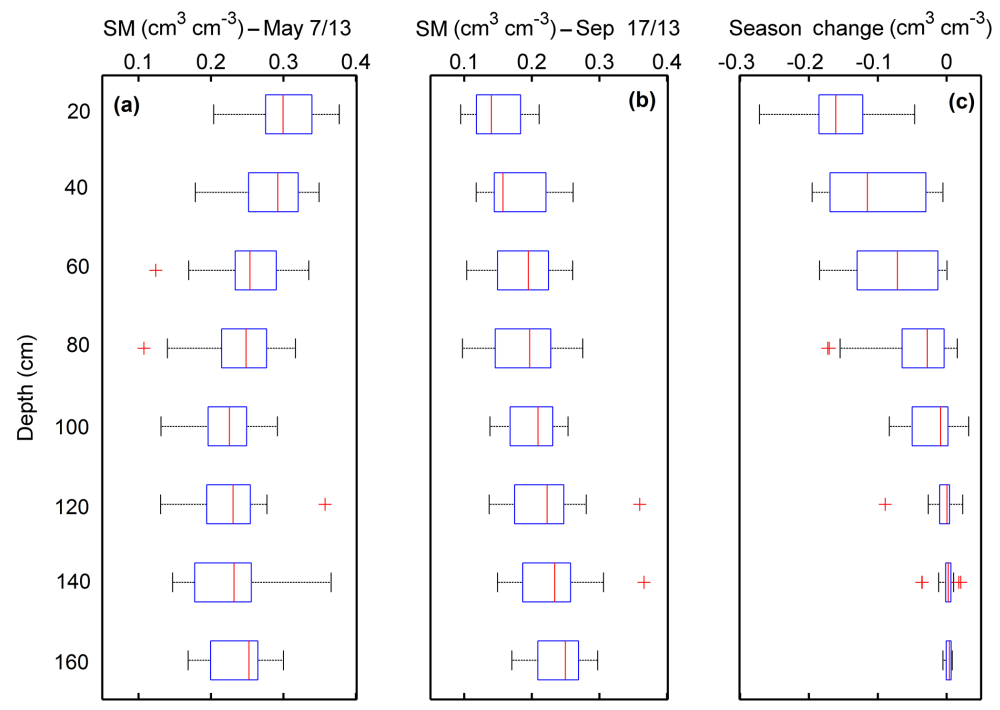

Figure 3. Spatial variability of soil moisture with depth; volumetric water content for 7 May 2013 and 17 September 2013, and season change (difference between 17 September 2013 and 7 May 2013). The boxplot indicates the median (red line), 25th and 75th percentile (edges of the box), and minimum and maximum (extent of whiskers) values.

was captured within the top $110 \mathrm{~cm}$ of the soil profile, with negligible changes below this. The change in soil moisture measured by the cosmic-ray neutron probe, represented as the $0-14 \mathrm{~cm}$ interval, was highly variable but accounted for less than $40 \%$ of the total seasonal change in moisture storage (Fig. 4, fraction of total cumulative storage change for 0-14 cm on 17 September 2013 and 20 October 2014).

\subsection{Depth-scaling approaches}

\subsubsection{Time stability}

The time stability of soil moisture at each neutron probe location was evaluated by examining the MRD (Eq. 4) during the 2013 season (Fig. 5). The locations which are most similar to field mean soil moisture content are those with an MRD near zero (e.g. 195D, 240D, and 240C). However, given that they have relatively large standard deviations, they cannot be considered time stable. Rather, location 285D is shown to be the most time-stable location as it has the smallest MRD stan- 

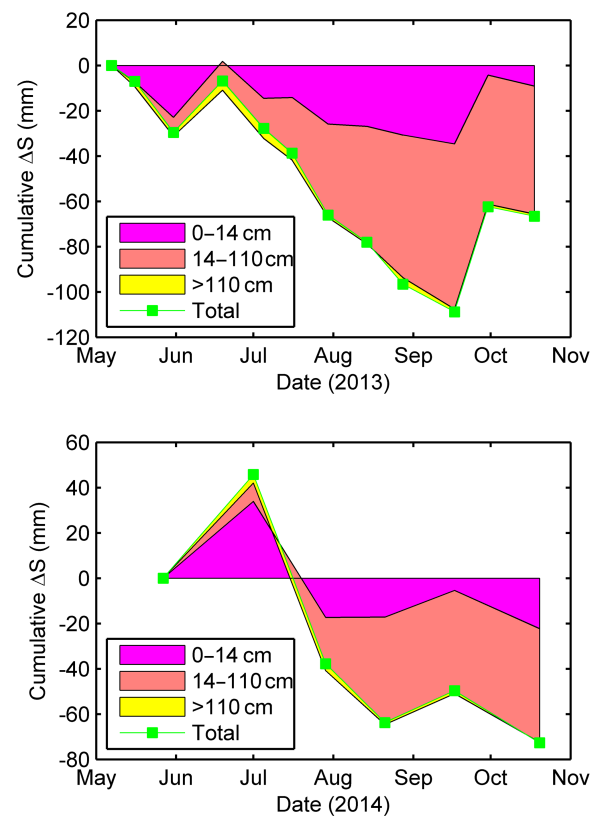

Figure 4. Cumulative change in storage with depth; 0-14 cm represents the cosmic-ray neutron probe measurements.

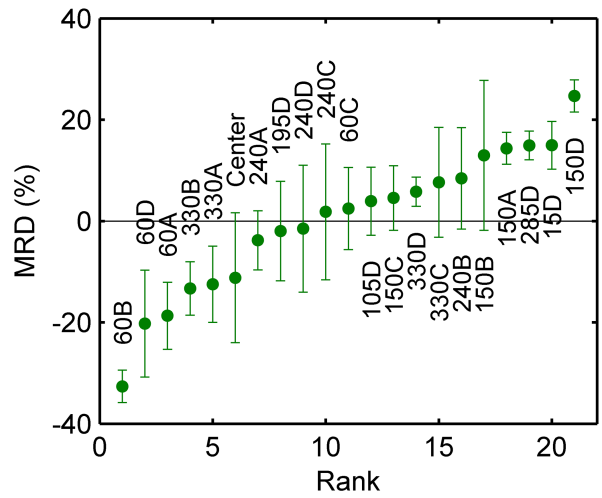

Figure 5. Average mean relative difference (MRD) \pm 1 SD for each neutron probe monitoring location.

dard deviation $(2.8 \%)$, closely followed by 330D (2.9\%). To upscale the soil moisture from $285 \mathrm{D}$ to field scale, a constant offset of $0.033 \mathrm{~cm}^{3} \mathrm{~cm}^{-3}$ was applied.

Several authors (e.g. Grayson and Western, 1998; Vachaud et al., 1985) have suggested that time-stable sites, in particular those that are also average representative (MRD near 0), may have average physical properties, i.e. topography, soil, or vegetation characteristics. However, at this site, none of the locations were considered both time-stable and average representative (Fig. 5). Figure 6 examines the elevation and bulk density $(0-80 \mathrm{~cm}$ average) of the time-stable and average representative sites, with respect to all monitored locations. The time-stable locations, those that have similar changes in soil moisture as the field mean, were found to
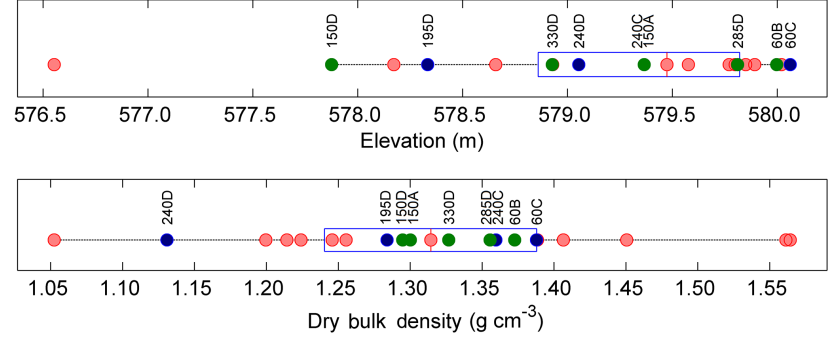

\begin{tabular}{|ll|}
\hline Average representative \\
- Time stable \\
Other \\
\hline
\end{tabular}

Figure 6. Physical characteristics of the time-stable and average representative sites. The boxplot indicates the median (red line), 25th and 75th percentile (edges of the box), and minimum and maximum (extent of whiskers) values of all point measurement locations.
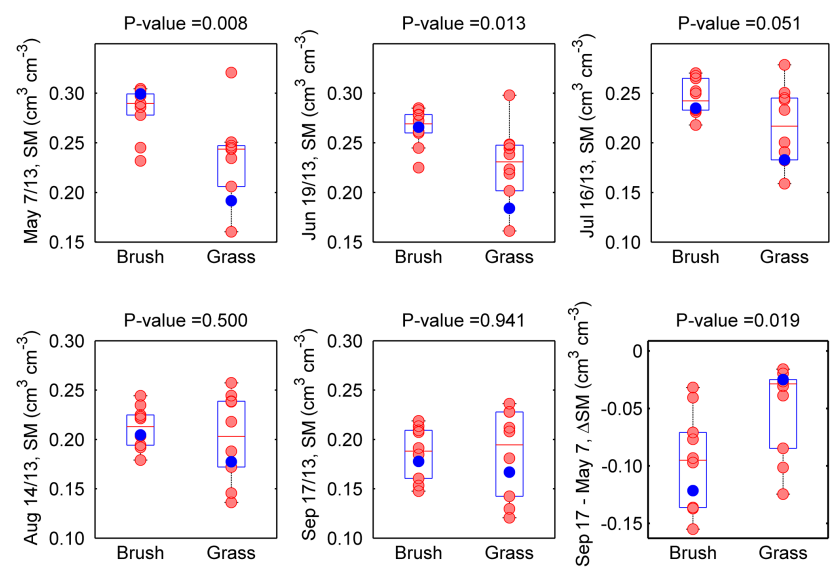

Figure 7. Variability of soil moisture storage for the two different vegetation groups shown by box and whisker plot, with the $p$ value from $t$ test indicating the chance of similar means. The number of grass and brush locations are both 10. Blue dots indicate the chosen grass and brush monitoring sites (60A and 150C, respectively).

have a bulk density near field average (clustered near the median value in Fig. 6), but no relation with elevation. The average representative sites showed no relation with either elevation or bulk density.

\subsubsection{Landscape unit}

The premise of using vegetation type to define similar response units for soil moisture depends on whether the units actually display differences in their mean values and in the variability of soil moisture. Box and whisker plots for select dates in 2013 (Fig. 7) show that for half of the dates a very noticeable difference in the median soil moisture storage between brush and grass units exists, but for the other plots the interquartile ranges overlap. A two-tailed independent samples $t$ test was used to determine if the means were different. 
Table 1. Exponential filter parameter values found from layer $1 \mathrm{ob}-$ servations and calibration.

\begin{tabular}{lc}
\hline Parameters & \multicolumn{1}{c}{ Value } \\
\hline \multicolumn{2}{l}{ Observation based } \\
\hline $\min (L 1)$ & 0.09 \\
$\max (L 1)$ & 0.47 \\
\hline Calibrated & \\
\hline $\min (L 2)$ & 0.13 \\
$\max (L 2)$ & 0.33 \\
$T$ & 44 \\
\hline
\end{tabular}

The $p$ value of the $t$ tests (displayed at the top of each graph in Fig. 7) indicates the likeliness that the means are statistically similar. During the earlier months, when soil moisture is higher, the means between the two vegetation types are statistically different at $95 \%$ confidence $(p$ value $<0.05)$. In the later months, under drier soil moisture conditions, the means are statistically similar, as indicated by the large $p$ values. The means of the seasonal change in storage between the two vegetation groups were found to be statistically different at $98 \%$ confidence. By the mixed results, it is unlikely that vegetation type is the best way to group the soil moisture measurements at this particular site.

The locations chosen to represent grass and brush, which were $60 \mathrm{~A}$ and $150 \mathrm{C}$, respectively, are indicated by the bluedots in Fig. 7. For the brush vegetation, location 150C represents the median soil moisture of this vegetation group well. However, for the grass vegetation group, location 60A represents the median change in soil moisture fairly well, but soil moisture values measured at this site are lower than the majority of the other grass sites. This suggests that the estimate of field-scale volumetric water content using this method, and these representative sites, is expected to be consistently low.

\subsubsection{Exponential filter}

Wilting point, field capacity, and total water capacity were not measured at the field site. These properties were available from a government agency soil survey (Ellis et al., 1970). However, the wilting point given was higher than some of the field average measurements of the neutron probe array. Using these soil properties would therefore yield significantly higher layer 2 soil moisture than the measured values. To get better results, both the minimum and maximum layer 2 bounds were calibrated in addition to the characteristic time length $(T)$ which represents the timescale of soil moisture variation (Albergel et al., 2008). The Monte Carlo simulations (Fig. 8) show that layer 2 minimum and maximum water contents are very sensitive, whereas the $T$ parameter is less sensitive, with values ranging $30-70$ days giving similar results.
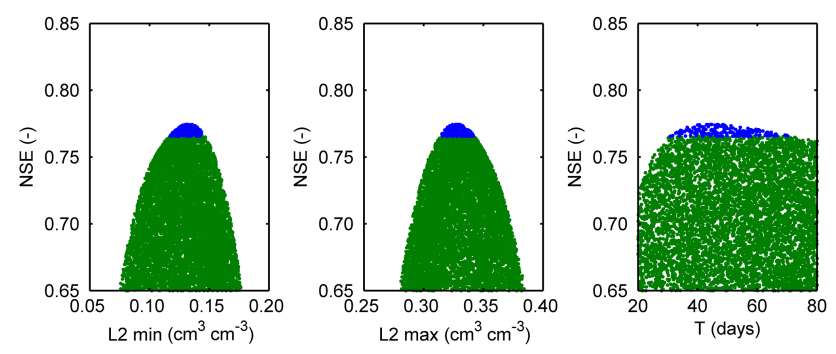

Figure 8. Sensitivity of the exponential filter parameters. Parameters were optimized based on the NSE. The blue dots indicate the top 200 combinations with the highest NSE, giving an indication of the sensitivity.
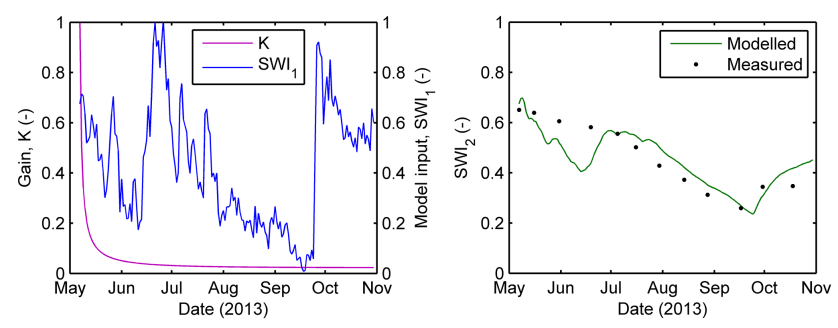

Figure 9. Input and output signals of the exponential filter using the optimized parameters from Table $1 . \mathrm{SWI}_{1}$ is the soil water index of the cosmic-ray neutron probe measurements.

The optimum value of $T$, and layer 2 soil moisture bounds are shown in Table 1. Layer 1 minimum and maximum were based on the 2013 cosmic-ray neutron probe data. The problem with this approach is that the layer 1 minimum and maximum bounds may not be assessed correctly when only using 1 year of data. For example, Wagner et al. (1999) used observations from 6 years to define layer 1 soil moisture bounds. It should be noted that the layer 1 minimum and maximum bounds have a high impact on the optimum layer 2 minimum and maximum bounds found through calibration.

Input and output signals of the exponential filter, using the optimum parameters, are shown in Fig. 9. The gain is shown to exponentially decay from its initialized value of 1 , and stay at a constant level (Fig. 9a). The gain is controlled by the $T$ parameter, as seen in Eq. (9). At lower $T$ values, the gain will level out quicker at a higher value. Comparison of the measured and modelled layer $2 \mathrm{SWI}\left(\mathrm{SWI}_{2}\right)$ is shown in Fig. 9b. A smaller gain produces a more damped $\mathrm{SWI}_{2}$ signal. Modelled $\mathrm{SWI}_{2}$ provides a better fit to the measured values starting at the end of June, after the gain becomes constant. The poorer performance in May and June may be related to higher gain values (caused by initializing the model at a gain of 1), which makes the model more sensitive to layer 1 soil moisture $\left(\mathrm{SWI}_{1}\right)$ measurements during this time period. 

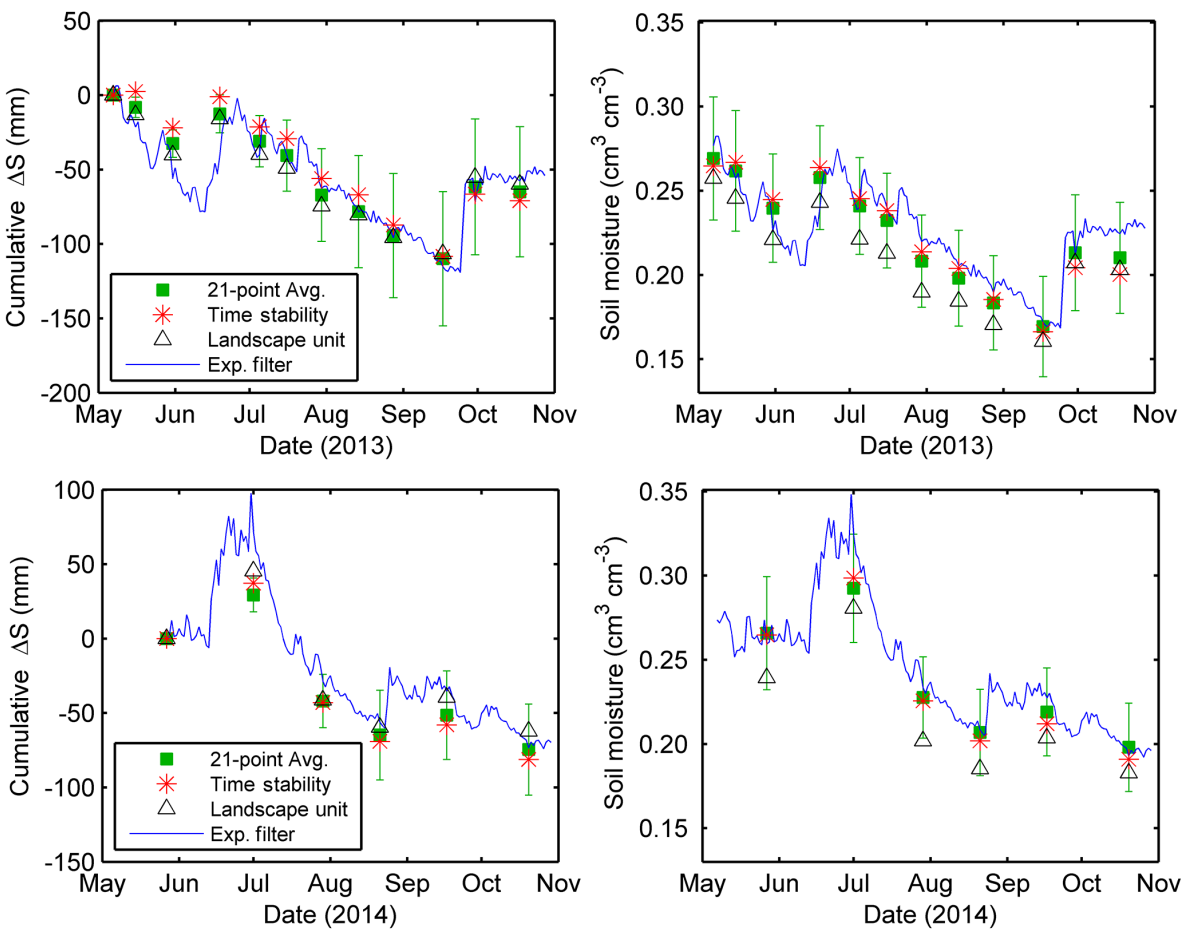

Figure 10. Volumetric water content and cumulative change of field-scale soil moisture as estimated by the depth-scaling methods for $0-110 \mathrm{~cm}$ in 2013 and 2014.

\subsection{Performance evaluation}

The cumulative changes in root zone storage and mean volumetric water content for the 2013 and 2014 seasons are shown in Fig. 10. Absolute values of volumetric water content provide a more rigorous test of the performance of the methods, while the cumulative change in storage is insensitive to systematic errors in the magnitude, but will be adequate for assessing annual water balances. The benchmark, neutron probe spatial average combined with the cosmicray neutron probe measurements, is shown in green as mean soil moisture $\pm 1 \mathrm{SD}$, which is based upon the spatial variability of soil moisture measured by the neutron probe array. Method performance of estimating field-scale volumetric water content was evaluated using the Pearson correlation coefficient $(R)$, root mean square error (RMSE), bias (BIAS), and NSE. The results are shown in Table 2.

The time stability approach performed well in estimating both field-scale volumetric water content and changes in soil moisture, and had the highest performance metrics in both $2013\left(\mathrm{RMSE}=0.006 \mathrm{~cm}^{3} \mathrm{~cm}^{-3}\right.$ ) and 2014 $\left(\mathrm{RMSE}=0.005 \mathrm{~cm}^{3} \mathrm{~cm}^{-3}\right)$.

The landscape unit approach provided good estimates of field-scale changes in soil moisture for both 2013 and 2014. The pattern of soil moisture change was accurately captured $(R>0.98)$, but the method exhibited a negative bias, where estimates of field-scale volumetric water content were consistently lower than the benchmark average. This result is
Table 2. Performance metrics of depth-scaling methods using instrumentation average as the control. Units of RMSE and BIAS are $\mathrm{cm}^{3} \mathrm{~cm}^{-3}$.

\begin{tabular}{lccrc}
\hline & $R$ & RMSE & BIAS & NSE \\
\hline $2013(n=12)$ & & & & \\
\hline Time stability & 0.984 & 0.006 & 0.001 & 0.962 \\
Landscape unit & 0.989 & 0.015 & -0.014 & 0.767 \\
Exponential filter & 0.952 & 0.010 & 0.002 & 0.902 \\
\hline $2014(n=6)$ & & & & \\
\hline Time stability & 0.999 & 0.005 & -0.003 & 0.975 \\
Landscape unit & 0.987 & 0.020 & -0.019 & 0.636 \\
Exponential filter & 0.972 & 0.014 & 0.006 & 0.817 \\
\hline
\end{tabular}

consistent with Fig. 7, where it was shown that the chosen locations, $60 \mathrm{~A}$ and $150 \mathrm{C}$, represented the change in soil moisture. The soil moisture measurements from $60 \mathrm{~A}$ were consistently lower than the median value for grass, and it was expected that the estimate of volumetric water content would be low.

The exponential filter provided good estimates of both field-scale volumetric water content and change in soil moisture over both years, with the metrics showing slightly poorer performance in $2014\left(\mathrm{RMSE}=0.014 \mathrm{~cm}^{3} \mathrm{~cm}^{-3}\right.$; $\mathrm{NSE}=0.817)$ due to the poor match with the spatial av- 
erage on 1 July 2014. This RMSE is lower than previous studies (RMSE of $0.022 \mathrm{~cm}^{3} \mathrm{~cm}^{-3}$ in Ceballos et al. (2005); RMSE of $0.049 \mathrm{~cm}^{3} \mathrm{~cm}^{-3}$ in Wagner et al., 1999) most likely because the method is being applied on a smaller scale $\left(<1 \mathrm{~km}^{2}\right)$ and the bounds of layer 2 have been calibrated. The cosmic-ray neutron probe also has a deeper measurement depth than satellite remote sensing instruments, and therefore less of the root zone needs to be modelled. An inherent advantage of the exponential filter method is that the estimates are of the same temporal resolution as the cosmicray neutron probe measurements, whereas estimates from the other methods are dependent on how frequently down-hole neutron probe measurements are taken.

Based on the similarities in performance between 2013 and 2014, all methods can be considered stable at this prairie pasture over the 2-year period. The time stability and the representative landscape unit approach rely on the spatial pattern of soil moisture staying constant with time. The consistent performance of these methods may be due to no physical changes to the environment occurring, i.e. the spatial pattern of vegetation stayed constant over the 2 years. Han et al. (2012) compared several upscaling methods, including time stability, and determined they were not temporally transferable at an agricultural site due to differences in rainfall and crop type between the 2 years. It is important to note that the 2014 season (May-August) received $46 \%$ more rain than the 2013 season. Despite the differences in precipitation the methods perform consistently.

\subsection{Spatial transferability}

The results of this study suggest that both the time-stable site and the exponential filter method would provide reliable estimates of field-scale soil moisture at the study site in subsequent years. However, these methods require calibration. In order for the methods to be applied more widely they must be able to be used at other locations with no calibration, or at least reduced calibration. The spatial average method comprised of observations from a 21-point neutron probe array. Although this method was assumed to be the most accurate, the averaging of many point observations is often not a logistically feasible long-term option for estimating field-scale soil moisture. In this section, we provide suggestions on how or if the remaining methods can be spatially transferred.

\subsubsection{Time stability}

In order for this method to be transferred to another site, the user would need to be able to locate the most time-stable site with only a small amount of work, or be able to identify the location of the site based on its physical characteristics. Studies (e.g. Grayson and Western, 1998; Jacobs et al., 2004; Teuling et al., 2006) have mainly focused on locating time-stable sites that are already average representative, so that an offset is not required. Teuling et al. (2006) found high uncertainty in the spatial mean estimate ( $\sim 75 \%$ of spatial variability) when a single survey was used to locate the average representative time-stable site, as opposed to a general uncertainty of $\sim 40 \%$ of the spatial variability when the seasonal dynamics were understood. There have also been mixed results in field studies on whether average representative sites have average physical characteristics. Teuling et al. (2006) examined time stability of root zone soil moisture and did not find average representative sites to have field average elevation or leaf area index. The average representative locations in this study were not time stable (Fig. 5) and did not have field average elevation or bulk density characteristics (Fig. 6). However, the locations that were time stable had field average bulk density (Fig. 6). For surface soil moisture, Jacobs et al. (2004) determined average representative sites were found mid-hillslope under specific soil textures. In general, root zone soil moisture may be more difficult than surface soil moisture to relate to physical characteristics, as it may incorporate an average from multiple soil layers. A study on the variability of root zone soil moisture in the Canadian prairies (Biswas et al., 2012), found root zone soil moisture to be strongly influenced by the depth of the $\mathrm{A}$ and $\mathrm{C}$ horizons, in addition to soil texture and bulk density. For root zone soil moisture, these studies show that time-stable sites may not be easily identified from their physical characteristics or with a single soil moisture survey. The time stability upscaling method would therefore be difficult to implement at sites lacking existing instrumentation.

\subsubsection{Landscape unit}

The landscape unit monitoring approach is one of the most feasible methods to implement in practice, requiring soil moisture instrumentation to be installed at only a single measurement location per vegetation type. This method is noncalibrated and large soil moisture variability could potentially exist within the vegetation groups. Therefore, the performance of this method is largely dependent on which locations are chosen to subjectively represent the vegetation types. In this study, the sites chosen represented the change in soil moisture well, but the chosen grass site provided consistently low water content estimates (Fig. 7). The landscape unit approach will be most effective in places where vegetation is the dominant control on soil moisture variability. The reliability of this method in general may be limited as other factors such as topography or soil properties may be of greater importance (e.g. Hawley et al., 1983; Western et al., 2004; Biswas et al., 2012).

\subsubsection{Exponential filter}

The exponential filter method may be the most promising in providing root zone soil moisture for fields where profile soil moisture is not monitored. The question is then how to parameterize the exponential filter on such a large scale. Soil 
hydraulic properties will need to be estimated in order to determine layer 1 and layer 2 soil moisture bounds, given that previous layer 1 measurements most likely will not exist and layer 2 cannot be calibrated as performed in this study. The regional soil hydraulic properties of the area available from soil survey data (Ellis et al., 1970) were not accurate for the pasture site studied here, most likely due to the map resolution. It may therefore be necessary to measure the local soil hydraulic properties to obtain higher accuracy. The effect of soil property errors was shown by Wagner et al. (1999) to cause a bias in the estimate that is dependent on soil type. Also, consideration of how to establish a suitable characteristic time length $(T)$ needs to be given. Several studies (Ceballos et al., 2005; Albergel et al., 2008; de Lange et al., 2008) have examined controls on $T$. The most important control on $T$ is modelling depth, with larger $T$ values being more suitable for greater modelling depths (Wagner et al., 1999; Ceballos et al., 2005; Albergel et al., 2008). Soil texture (de Lange et al., 2008) and climate (Albergel et al., 2008) were also found to have an influence on $T$. Although $T$ may be affected by a number of factors, the results of this study and others (e.g. Wagner et al., 1999; Ceballos et al., 2005; Albergel et al., 2008) show that the parameter has relatively low sensitivity when considering the entire root zone. Because the acceptable range of $T$ values is usually relatively large, accurate parameterization may not be necessary to obtain suitable soil moisture estimates.

\section{Conclusions}

In this study, the cosmic-ray neutron probe was used along with different depth-scaling methods to estimate field-scale root zone soil moisture. The cosmic-ray neutron probe was found to provide good estimates of surface soil moisture for this site through comparison with precipitation events and gravimetric sampling. The effective measurement depth generally ranged $10-20 \mathrm{~cm}$, which was determined to account for less than $40 \%$ of the seasonal change in soil water storage. This illustrates that depth-scaling is necessary for the cosmic-ray neutron probe measurements to be representative of root zone soil moisture.

Three different depth-scaling methods were used to estimate field-scale soil moisture over the entire root zone. Their performance, in terms of estimating volumetric water content and changes in moisture storage, was evaluated against the 21-point spatial average. The time stability method provided the best estimates of field-scale root zone soil moisture (RMSE $=0.005 \mathrm{~cm}^{3} \mathrm{~cm}^{-3}$ ) during both the calibration and validation years, followed by the exponential filter (RMSE of 0.010 and $0.014 \mathrm{~cm}^{3} \mathrm{~cm}^{-3}$ for the calibration and validation years, respectively). The landscape unit approach, based on the monitoring locations chosen, showed a consistent negative bias and was only able to estimate moisture changes well. The ease of applying these methods to sites without ex- isting instrumentation was discussed. Intensive soil moisture monitoring is necessary to determine the time-stable location, making application of the time stability method difficult. The exponential filter may be easier to apply given that the main parameter, the characteristic time length, has relatively low sensitivity. Soil hydraulic properties, which are also important for the exponential filter method, can be obtained from regional soil survey data; however, they may need to be measured locally for better accuracy. Considering both performance and ease of spatial transferability, the exponential filter method is the most suitable for scaling cosmic-ray neutron probe data. Further studies are necessary to understand the full potential of the exponential filter method in estimating root zone soil moisture from cosmicray neutron probe data.

Acknowledgements. The authors would like to thank Bruce Johnson, Dell Bayne, and Xicai Pan for their assistance with data collection. Additionally, Environment Canada is acknowledged for their ongoing cooperation and support in operating the Brightwater Creek Research basin. Funding for this research was provided by the Natural Sciences and Engineering Research Council of Canada (NSERC) through a discovery grant awarded to A. Ireson titled "Groundwater - surface water interactions in the prairies", and the program of the Canada Excellent Research Chair at the Global Institute for Water Security, University of Saskatchewan.

Edited by: N. Romano

\section{References}

Albergel, C., Rüdiger, C., Pellarin, T., Calvet, J.-C., Fritz, N., Froissard, R., Suquia, D., Petitpa, A., Piguet, B., and Martin, E.: From near-surface to root zone soil moisture using an exponential filter: an assessment of the method based on in-situ observations and model simulations, Hydrol. Earth Syst. Sci., 12, 1323-1337, doi:10.5194/hess-12-1323-2008, 2008.

Albergel, C., Rüdiger, C., Carrer, D., Calvet, J.-C., Fritz, N., Naeimi, V., Bartalis, Z., and Hasenauer, S.: An evaluation of ASCAT surface soil moisture products with in-situ observations in Southwestern France, Hydrol. Earth Syst. Sci., 13, 115-124, doi:10.5194/hess-13-115-2009, 2009.

Biswas, A., Chau, H. W., Bedard-Haughn, A. K., and Si, B. C.: Factors controlling soil water storage in the hummocky landscape of the Prairie Pothole Region of North America, Can. J. Soil Sci., 92, 649-663, doi:10.4141/cjss2011-045, 2012.

Bogena, H. R., Huisman, J. A., Baatz, R., Hendriks Franssen, H.-J., and Vereecken, H.: Accuracy of the cosmic-ray soil water content probe in humid forest ecosystems: The worst case scenario, Water Resour. Res., 49, 5778-5791, doi:10.1002/wrcr.20463, 2013.

Brocca, L., Melone, F., Moramarco, T., Wagner, W., Naeimi, V., Bartalis, Z., and Hasenauer, S.: Improving runoff prediction through the assimilation of the ASCAT soil moisture product, Hydrol. Earth Syst. Sci., 14, 1881-1893, doi:10.5194/hess-141881-2010, 2010a. 
Brocca, L., Melone, F., Moramarco, T., and Morbidelli, R.: Spatial-temporal variability of soil moisture and its estimation across scales, Water Resour. Res., 46, W02516, doi:10.1029/2009WR008016, 2010 b.

Calvet, J.-C. and Noilhan, J.: From near-surface to root zone soil moisture using year-round data, J. Hydrometeorol., 1, 393-411, 2000.

Ceballos, A., Scipal, K., Wagner, W., and Martínez-Fernández, J.: Validation of ERS scatterometer-derived soil moisture data in the central part of the Duero Basin, Spain, Hydrol. Process., 19, 1549-1566, doi:10.1002/hyp.5585, 2005.

Crow, W. T., Berg, A. A., Cosh, M. H., Loew, A., Mohanty, B. P., Panciera, R., de Rosnay, P., Ryu, D., and Walker, J. P.: Upscaling sparse based soil moisture observations for the validation of coarse-resolution satellite soil moisture products, Rev. Geophys., 50, RG2002, doi:10.1029/2011RG000372, 2012.

de Lange, R., Beck, R., van de Giesen, N., Fiesen, J., de Wit, A., and Wagner, W.: Scatterometer-derived soil moisture calibrated for soil texture with a one-dimensional waterflow model, IEEE T. Geosci. Remote, 46, 4041-4049, doi:10.1109/TGRS.2008.2000796, 2008.

Dong, J., Ochsner, T. E., Zreda, M., Cosh, M. H., and Zou, C. B.: Calibration and validation of the COSMOS rover for surface soil moisture measurement, Vadose Zone J., 13, doi:10.2136/vzj2013.08.0148, 2014

Ellis, J. G., Acton, D. F., and Moss, H. C.: The Soils of the Rosetown Map Area: 72-O Saskatchewan, Publ. S3, Sask. Institute of Pedology, Saskatoon, Sask., 159 pp., 1970.

Environment Canada: Canadian climate normals: 1980-2010 for Davidson, Saskatchewan, available at: http://climate.weather.gc. ca/climate_normals/ (last access: November 2015), 2014.

Ford, T. W., Harris, E., and Quiring, S. M.: Estimating root zone soil moisture using near-surface observations from SMOS, Hydrol. Earth Syst. Sci., 18, 139-154, doi:10.5194/hess-18-1392014, 2014.

Franz, T. E., Zreda, M., Rosolem, R., and Ferré, T. P. A.: Field validation of a cosmic-ray neutron sensor using a distributed sensor network, Vadose Zone J., 11, doi:10.2136/vzj2012.0046, 2012a.

Franz, T. E., Zreda, M., Ferré, T. P. A., Rosolem, R., Zweck, C., Stillman, S., Zeng, X., and Shuttleworth, W. J.: Measurement depth of the cosmic ray soil moisture probe affected by hydrogen from various sources, Water Resour. Res., 48, W08515, doi:10.1029/2012WR011871, 2012b.

Gao, X., Wu, P., Zhao, W., Zhang, B., Wang, J., and Shi, Y.: Estimating the spatial means and variability of root zone soil moisture in gullies using measurements from nearby uplands, J. Hydrol., 276, 28-41, doi:10.1016/j.jhydrol.2012.10.030, 2013.

Grayson, R. B. and Western, A. W.: Towards areal estimation of soil water content from point measurements: Time and space stability of mean response, J. Hydrol., 207, 68-82, 1998.

Han, E., Heathman, G. C., Merwade, V., and Cosh, M. H.: Application of observation operators for field scale soil moisture averages and variances in agricultural landscapes, J. Hydrol., 444445, 34-50, doi:10.1016/j.jhydrol.2012.03.035, 2012.

Han, X., Franssen, H.-J. H., Rosolem, R., Jin, R., Li, X., and Vereecken, H.: Correction of systematic model forcing bias of CLM using assimilation of cosmic-ray neutrons and land surface temperature: a study in the Heihe Catchment, China, Hy- drol. Earth Syst. Sci., 19, 615-629, doi:10.5194/hess-19-6152015, 2015.

Hawdon, A., McJannet, D., and Wallace, J.: Calibration and correction procedures for cosmic-ray neutron soil moisture probes located across Australia, Water Resour. Res., 50, 5029-5043, doi:10.1002/2013WR015138, 2014.

Hawley, M. E., Jackson, T. J., and McCuen, R. H.: Surface soil moisture variation on small agricultural watersheds, J. Hydrol., 62, 179-200, 1983.

Heathman, G. C., Starks, P. J., Ahuja, L. R., and Jackson, T. $\mathrm{J}$.: Assimilation of surface soil moisture to estimate profile soil water content, J. Hydrol., 279, 1-17, doi:10.1016/S00221694(03)00088-X, 2003.

Hornbuckle, B., Irvin, S., Franz, T., Rosolem, R., and Zweck, C.: The potential of the COSMOS network to be a source of new soil moisture information for SMOS and SMAP, in: Proc. IEEE Int. Geosci. Remote Sens. Symp., 22-27 July 2012, Munich, Germany, 1243-1246, 2012.

Jacobs, J. M., Mohanty, B. P., Hsu, E.-C., and Miller, D.: SMEX02: Field scale variability, time stability and similarity of soil moisture, Remote Sens. Environ., 92, 436-446, doi:10.1016/j.rse.2004.02.017, 2004.

Kerr, Y. H., Waldteufel, P., Wigneron, J. P., Delwart, S., Cabot, F., Boutin, J., Escorihuela, M., Font, J., Reul, N., Gruhier, C., Juglea, S., Drinkwater, M., Hahne, A., Martín-Neira, M., and Mecklenburg, S.: The SMOS mission: New tool for monitoring key elements of the global water cycle, Proc. IEEE, 98, 666-687, doi:10.1109/JPROC.2010.2043032, 2010.

Köhli, M., Schrön, M., Zreda, M., Schmidt, U., Dietrich, P., and Zacharias, S.: Footprint characteristics revised for tield-scale soil moisture monitoring with cosmic-ray neutrons, Water Resour. Res., 51, 5772-5790, doi:10.1002/2015WR017169, 2015.

Mohanty, B. P. and Skaggs, T. H.: Spatio-temporal evolution and time-stable characteristics of soil moisture within remote sensing footprints with varying soil, slope, and vegetation, Adv. Water Resour., 24, 1051-1067, 2001.

Ragab, R.: Towards a continuous operational system to estimate the root zone soil moisture from intermittent remotely sensed surface moisture, J. Hydrol., 173, 1-25, 1995.

Rivera Villarreyes, C. A., Baroni, G., and Oswald, S. E.: Integral quantification of seasonal soil moisture changes in farmland by cosmic-ray neutrons, Hydrol. Earth Syst. Sci., 15, 3843-3859, doi:10.5194/hess-15-3843-2011, 2011.

Rivera Villarreyes, C. A., Baroni, G., and Oswald S. E.: Inverse modelling of cosmic-ray soil moisture for field scale soil hydraulic parameters, Eur. J. Soil Sci., 65, 876-886, doi:10.1111/ejss.12162, 2014.

Rosolem, R., Hoar, T., Arellano, A., Anderson, J. L., Shuttleworth, W. J., Zeng, X., and Franz, T. E.: Translating aboveground cosmic-ray neutron intensity to high-frequency soil moisture profiles at sub-kilometer scale, Hydrol. Earth Syst. Sci., 18, 4363 4379, doi:10.5194/hess-18-4363-2014, 2014.

Shuttleworth, J., Rosolem, R., Zreda, M., and Franz, T.: The Cosmic-ray Soil Moisture Interaction Code (COSMIC) for use in data assimilation, Hydrol. Earth Syst. Sci., 17, 3205-3217, doi:10.5194/hess-17-3205-2013, 2013.

Teuling, A. J., Uijlenhoet, R., Hupet, F., van Loon, E. E., and Troch, P. A.: Estimating spatial mean root zone soil moisture from 
point-scale observations, Hydrol. Earth Syst. Sci., 10, 755-767, doi:10.5194/hess-10-755-2006, 2006.

Vachaud, G., Passerat de Silons, A., Balabanis, P., and Vauclin, M.: Temporal stability of spatially measured soil water probability density function, Soil Sci. Soc. Am. J., 49, 822-828, 1985.

Wagner, W., Lemoine, G., and Rott, H.: A method for estimating soil moisture from ERS scatterometer and soil data, Remote Sens. Environ., 70, 191-207, 1999.

Walker, J. P., Willgoose, G. R., and Kalma, J. D.: One-dimensional soil moisture profile retrieval by assimilation of near-surface observations: a comparison of retrieval algorithms, Adv. Water Resour., 24, 631-650, 2001.
Western, A. W., Zhou, S. L., Grayson, R. B., McMahon, T. A., Blöschl, G., and Wilson, D. J.: Spatial correlation of soil moisture in small catchments and its relationship to dominant spatial hydrological processes, J. Hydrol., 286, 113-134, doi:10.1016/j.jhydrol.2003.09.014, 2004.

Zhao, Y., Peth, S., Wang, X. Y., Lin, H., and Horn, R.: Controls of surface soil moisture spatial patterns and their temporal stability in a semi-arid steppe, Hydrol. Process., 24, 2507-2519, doi:10.1002/hyp.7665, 2010.

Zreda, M., Shuttleworth, W. J., Zeng, X., Zweck, C., Desilets, D., Franz, T., and Rosolem, R.: COSMOS: The COsmic-ray Soil Moisture Observing System, Hydrol. Earth Syst. Sci., 16, 1-21, doi:10.5194/hess-16-1-2012, 2012 